\title{
Load, Work, and Velocity of Muscle Shortening of the Left Ventricle in Normal and Abnormal Human Hearts*
}

\author{
D. E. L. WILCKEN $\dagger$ \\ (From the Department of Medicine, University of New South Wales, Prince Henry Hospital, \\ Sydney, Australia)
}

When a muscle contracts against a load less than one that would result in an isometric contraction, it shortens and does external work. In skeletal muscle at a particular initial length, and in heart muscle at a particular length and inotropic state, the extent and speed of shortening and the efficiency of the contraction depend upon the load (2-5). In an earlier study we showed that in the normal conscious dog at rest the systemic load and the left ventricle were so matched that during contraction maximal external work was done and maximal power was transferred to the systemic circulation (6). These conclusions were reached by studying successive contractions at different loads, but the load itself was not measured directly. The present study concerns the development of methods to measure the load in man, based on ventricular volume and pressure measurements. The relationships between external work and power transfer, velocity of muscle shortening, and load during left ventricular contraction were investigated.

\section{Methods}

Theoretical considerations. The relation between force, and pressure and volume in the heart was recognized by Stephen Hales (7). In recent years it has been outlined in detail by several authors $(8,9)$. The force acting radially on the inner surface of the ventricle at any time during systole is the product of the intraventricular pressure and surface area at that time. If the left ventricle is assumed to be a sphere (surface area $=\pi \mathrm{D}^{2}$ ), the mean force acting on the ventricle over the whole of systole $\left(\bar{F}_{\mathrm{T}}\right)$ may be ex-

* Submitted for publication November 23, 1964; accepted April 22, 1965.

This work was supported by grant no. G.168 from the National Heart Foundation of Australia. Some of these data were presented at the February 1965 meeting of the Australian Physiological Society and appeared in abstract form (1).

† Senior Research Fellow of the National Heart Foundation of Australia. Address requests for reprints to Dr. D. E. L. Wilcken, Dept. of Medicine, Prince Henry Hospital, Little Bay, N. S. W. Australia. pressed as:

$$
\overline{\mathrm{F}}_{\mathrm{T}}=\frac{\pi \int_{\mathrm{t}_{1}}^{\mathrm{t}_{2}} \mathrm{PD}^{2} \cdot \mathrm{dt}}{\mathrm{t}_{2}-\mathrm{t}_{1}},
$$

where $\bar{F}_{T}$ is the mean force opposing ventricular ejection; $P$ is the instantaneous intraventricular pressure during systole; $\mathrm{D}$ is the instantaneous diameter during systole of the ventricle, which is assumed to be spherical; $t_{1}$ is the time at end diastole; and $t_{2}$ is the time at end systole. This is taken as the point at the end of ventricular contraction at which the intraventricular pressure falls to its lowest level. If the walls and the cavity of the ventricle, which is assumed to be spherical, are considered to be transected by an imaginary plane that passes through the equator, the mean force tending to separate the ventricle into two hemispheres during contraction $\left(\overline{\mathrm{F}}_{\mathbf{M}}\right)$ is related to the mean force opposing ejection $\left(\overline{\mathrm{F}}_{\mathrm{T}}\right)$ in the ratio of $r^{2} / D^{2}$ (where $r=$ radius), i.e., 0.25 . This is the resultant mean force $\left(\bar{F}_{\mathbf{M}}\right)$ exerted by all the myocardial fibers perpendicular to this plane.

In terms of the model there are periods at the beginning and at the end of systole, corresponding to isovolumetric contraction and relaxation, during which there is no fiber shortening and no change in D. The forces opposing ejection during these phases of systole can be determined if end-diastolic and end-systolic volumes and intraventricular pressure are measured (volume of a sphere $=0.5237 \mathrm{D}^{3}$ )

During ejection the muscle fibers shorten and $\mathrm{D}$ changes. Fiber length is represented by circumference $(\pi \mathrm{D})$. Provided aortic pressure is also measured to record the ejection time, values for $\mathrm{D}$ during ejection could be obtained if the circumference of the left ventricle shortened at a constant rate. If this latter is assumed, values for surface area can be found throughout ejection. Values for $\bar{F}_{T}$ and $\bar{F}_{M}$ may then be calculated from Equation 1 from the values for surface area and intraventricular pressure.

In the first part of this study the hypothesis that the circumference of the left ventricle shortens at a relatively constant rate was tested in dogs under physiological conditions, and the errors introduced into the calculation of the forces opposing ejection by using this assumption were evaluated. In the second part this assumption was applied to man in order to calculate the force opposing left ventricular ejection.

Dog experiments. In 6 dogs under general anesthesia, coreless flow transducers were implanted around the root 
of the aorta as previously described (6). About a week later, under local anesthesia, a catheter with a micromanometer of high frequency response attached to its tip (Telco intracardiac manometer) was introduced through either the femoral or carotid arteries and passed into the left ventricle. The signals from the flow transducers were recorded by a sine-wave electromagnetic flowmeter of the type described by Elliott, Hoffman, and Guz (10) and displayed on a photographic recorder. ${ }^{1}$

With the dog lying undisturbed and breathing quietly, aortic flow (Q) and left ventricular pressures were recorded simultaneously at a paper speed of $200 \mathrm{~mm}$ per second. The dogs used had been frequently handled and were trained to lie quietly on a table, so that with a liberal use of local anesthesia it was possible to make these measurements with the dog fully conscious and co-operative and without apparent discomfort to it. The flow transducers were calibrated in vivo for each animal by recording three dye dilution curves simultaneously with the flow signals. Cardiogreen was used as the indicator. Changes in dye concentration were sensed with a Gilford densitometer model IR, and a constant flow withdrawal system was used. ${ }^{2}$

The end-systolic and end-diastolic volumes were not measured in these dogs, but were calculated from the stroke volume and from assumed values of $30 \%, 50 \%$, and $70 \%$ for the ratio of end-systolic to end-diastolic volume (ESV/EDV). A value of $50 \%$ is approximately that found for this ratio in dogs in good condition by Chapman, Baker, and Mitchell (11), using biplane cineangiography, and by Holt (12), Swan and Beck (13), Rapaport, Wiegand, and Bristow (14), and Wilcken (15), using the indicator dilution principle. It was not thought necessary to measure actual values for $\mathrm{ESV} / \mathrm{EDV}$ as absolute values for force and shortening rate were not under consideration in the dog experiments. The range $30 \%$ to $70 \%$ for $\mathrm{ESV} / \mathrm{EDV}$ certainly embraces the values that were actually present in these dogs.

Allowing for a delay of from 2.5 to $5 \mathrm{msec}$ in the flowmeter (10), measurements of flow and pressure were made at 10 -msec intervals throughout systole. The amount of blood $(\mathrm{V})$ left in the ventricle at each time interval throughout ejection was calculated by subtracting the integrated ejected volumes from the EDV, since $Q=-\mathrm{dV} / \mathrm{dt}$. The circumference of the inner surface of the ventricle $(\pi \mathrm{D})$ was calculated at each time interval from the volume of the ventricle (volume $=\mathrm{KD}^{3}$; therefore circumference $=\pi \sqrt[3]{\mathrm{V} / \mathrm{K})}$. The rate of shortening of the circumference was calculated at each 20 -msec interval during ejection.

The circumterence found was compared with that which would have obtained had the muscle as a whole been shortening at a constant rate. The surface area $\left(\pi D^{2}\right)$ at each interval was also calculated (surface area $=\pi\left[\sqrt[3]{\mathrm{V} / \mathrm{K}]^{2}}\right)$, both from the volumes obtained by subtraction of the integrated ejected volumes and from those that would have been present if the ventricular

${ }^{1}$ Model DR8, Electronics for Medicine, White Plains, N. Y.

${ }^{2}$ Constant flow system model 105-S, Gilford Instrument Laboratories, Oberlin, Ohio. muscle as a whole were shortening at a constant rate Each series of values for surface area was used to find from Equation 1 a value for the mean force opposing ejection. Two beats of widely differing stroke volume were calculated in this way for each of the six dogs studied.

Observations on man. The results showed that, in terms of the model, the assumption of a constant rate of muscle shortening introduced only a small error in the calculation of the mean force opposing shortening (see below), and so the force was calculated in this way in a group of patients who, for various clinical reasons, were undergoing left heart studies. The relevant clinical data and the routine data obtained at catheterization are shown in Table I. In no patient was there clinical or hemodynamic evidence of incompetence of either the mitral or aortic valve.

The patients studied were grouped as follows. There were eight patients (Cases 1 to 8 ) in whom there was no evidence of any abnormality of the left ventricle as judged by conventional criteria. These patients were investigated either because of systolic murmurs subsequently found to be innocent, or with a view to doing pulmonary angiography in patients with episodes of chest pain suspected of being due to pulmonary embolism. Five patients (Cases 9 to 13) had chronic rheumatic heart disease with isolated mitral stenosis as the sole valvular lesion. In these, left ventricular abnormality could not be excluded because of the rheumatic etiology. The other patient in this group, Case 14, had thromboembolic pulmonary hypertension (resting pulmonary arteriolar resistance of 440 dynes per $\mathrm{cm}^{5}$ ) of the microembolic type and had lowered arterial oxygen saturation at rest (arterial saturation, $87 \%$ ). Because of these findings, left ventricular abnormality could not be excluded. In seven patients (Cases 15 to 21) definite left ventricular abnormality was present (Table I). Four patients (Cases 18 to 21) had elevated end-diastolic pressures at rest.

The patients were studied in the mornings at least 2 hours after a light breakfast and either with or without light sedation (100 to $200 \mathrm{mg}$ pentobarbital an hour before the study). The left heart was catheterized using the technique described by Brockenbrough and Braunwald (16). Left ventricular volume and pressure were measured simultaneously during a "steady state" as judged by pulse rate, blood pressure, respiration, and general composure of the patient. Left ventricular volume was measured using the indicator dilution principle. The methods used to measure left ventricular volume, together with experimental evidence for their accuracy in man, have been presented elsewhere (15).

In the present study, as previously, $5 \mathrm{mg}$ of cardiogreen in $4 \mathrm{ml}$ of solution was injected rapidly into the left ventricle through a Brockenbrough catheter with multiple terminal openings. Beat by beat changes in indicator concentration in the ejected blood were detected by sampling at high flow rates (approximately $1 \mathrm{ml}$ per second) just downstream from the aortic valve through a no. 5 thin-walled spray-tipped catheter, 32 to $36 \mathrm{~cm}$ in length, introduced through the axillary artery and connected to a Gilford densitometer model 103 (IR). The time constant 
of the densitometer was shortened so that $90 \%$ of the full response to a square wave input occurred in less than 0.04 seconds. The effective dead space of the assembled cuvette and sampling catheter was $0.34 \mathrm{ml}$. The $90 \%$ response time of the whole system was approximately 0.6 second, but this depended on the sampling rate which it was possible to attain, and this varied slightly from patient to patient.

Steady flow rates were obtained by using a Gilford constant flow system (model 105-S). Pressure was measured with Sanborn pressure transducers from a zero of $5 \mathrm{~cm}$ vertically below the sternal angle (with the patient supine) and recorded simultaneously with the dilution curve on a Sanborn direct writing recorder at a speed of $25 \mathrm{~mm}$ per second. The curves were calibrated immediately after the study by drawing arterial blood, freshly drawn from the patient and containing known concentrations of indicator, through the densitometer at the same flow rate as during the study.

Stroke volume (SV) was calculated according to the Stewart-Hamilton method by determining the area under the discontinuous dilution curve, but modified so that the mean concentration at each beat was measured (12). The time interval was therefore 1 beat rather than 1 second. The concentrations were plotted semilogarithmically, and the exponential decline was extrapolated to a concentration of $0.1 \mathrm{mg}$ per $\mathrm{L}$ (Figures $3 \mathrm{~B}$ and $4 \mathrm{~B}$ ). The end-diastolic volume (EDV) was calculated as described by Holt (12) from the equation:

$$
\mathrm{EDV}=\frac{\mathrm{SV}}{1-\frac{\mathrm{C}_{\mathrm{N}}}{\mathrm{C}_{\mathrm{N}-1}}},
$$

where $\mathrm{C}_{\mathrm{N}}$ and $\mathrm{C}_{\mathrm{N}-1}$ are the concentrations of indicator in the blood ejected at beats $\mathrm{N}$ and $\mathrm{N}-1$ during the exponential decay of the curve, and the ratio $C_{N} / C_{N-1}$ is the average of the ratios of the concentrations at successive beats during the exponential part of the curve.

Left ventricular pressure was recorded through the Brockenbrough catheter. A three-way tap was attached to it so that with the completion of the injection the catheter could immediately be connected to a pressure transducer. Pressure measurements were made at 20msec intervals during beats occurring at end-expiration. The intrapleural pressures were not measured in these patients, but an arbitrary value of $-3 \mathrm{~mm} \mathrm{Hg}$ was assumed to represent the pressure within the thorax at the functional residual capacity of the lungs, and $3 \mathrm{~mm} \mathrm{Hg}$ was therefore added to all pressure measurements. The ejection time was measured from the aortic pressure recorded through the sampling catheter immediately before the inscription of the dilution curve.

The external work performed in each beat was calculated from the product of the mean ejection pressure minus the end-diastolic pressure, and the stroke volume. It is expressed as kilogram-centimeters. Power transferred to the systemic circulation was calculated from the product of stroke work and heart rate and expressed as kilogramcentimeters per second. The mean force opposed averaged throughout the cardiac cycle (systole and diastole) was calculated from the product of $\overline{\mathrm{F}}_{\mathbf{T}}$, and the proportion of each minute spent in systole, i.e., the mean force opposed $=\left[\bar{F}_{\mathrm{T}}\left(\mathrm{T}_{\mathrm{s}} \times \mathrm{HR}\right)\right] / 60$ where $\mathrm{T}_{\mathrm{s}}$ is the systolic time per beat in seconds and HR (heart rate) in beats per minute. It is expressed in kilograms.

\section{Results}

Figure 1A shows an example of the instantaneous flow and pressure curves obtained in the dogs. They are representative of those from which the instantaneous circumferential shortening and the tangential force in the wall $\left(\overline{\mathrm{F}}_{\mathbf{M}}\right)$ were calculated. In Figure 1B the calculated length of endocardial circumference is plotted at $10-\mathrm{msec}$ intervals throughout the ejection period for each of three hypothetical end-diastolic volumes based on ESV/ EDV ratios of $30 \%, 50 \%$, and $70 \%$. When the variations in circumference with time throughout ejection are compared with a linear relationship between the two, the differences are not unduly large (Figure 1B). This was a consistent finding in all the dogs studied.

These findings encouraged the view that if a constant rate of circumferential shortening were assumed, any errors introduced in the calculation of the net tangential force $\left(\bar{F}_{M}\right)$ developed in the wall in that circumference would be small. In Figure $1 \mathrm{C}, \overline{\mathrm{F}}_{\mathbf{M}}$ is plotted against time during the ejection period for each of the three end-diastolic volumes. The diameter $\mathrm{D}$ of Equation 1 has been obtained in two ways: $a$ ) from the instantaneous ejection rate and the relationships, $Q=-d v / d t$ and $\mathrm{V}=\mathrm{KD}^{3}$, and $b$ ) from $\mathrm{V}=\mathrm{KD}^{3}$ and assuming a constant rate of circumferential shortening. The differences in the values obtained by each method for instantaneous force and mean force are clearly small. The values for mean force obtained by method $b$ differed from those obtained by method $a$ by $-2 \%$ at ESV/EDV of $30 \%$, $-0.16 \%$ at $\mathrm{ESV} / \mathrm{EDV}$ of $50 \%$, and $+0.2 \%$ at $\mathrm{ESV} / \mathrm{EDV}$ of $70 \%$ in the representative example shown. The differences in all experiments for the instantaneous and mean values were consistently small, and for the mean values this is illustrated in Figure 2. In this graph are plotted the values for $\overline{\mathrm{F}}_{\mathrm{M}}$ obtained by each method in 12 beats in the six dogs studied. In each beat $\bar{F}_{\mathbf{M}}$ is calculated for three end-diastolic volumes given by the three ESV/EDV ratios quoted. With the ESV/EDV 


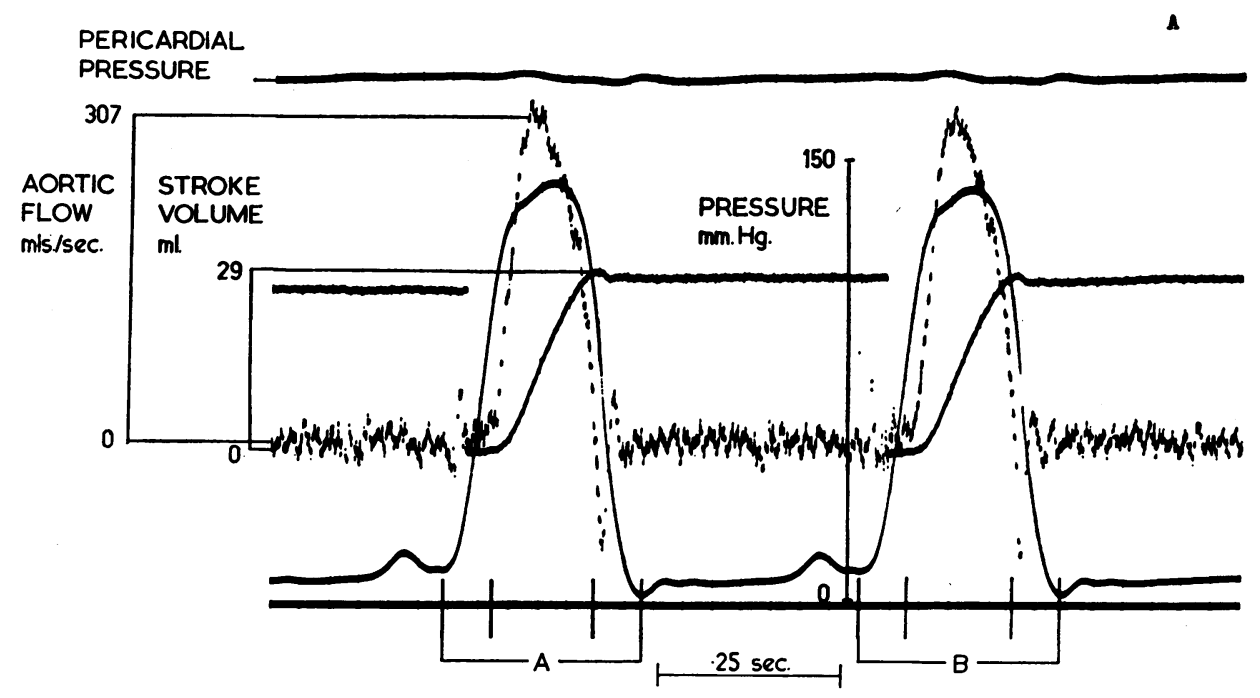

Fig. 1 A. Representative ReCORd of Simultaneous aORTIC Flow AND INTRAVENTRICUlaR PRESSURE MEASUREMENTS IN A CONSCIOUS DOG. Changes in intrathoracic pressure were recorded from a polyvinyl catheter chronically implanted in the pericardial space. The zero for this pressure is not shown, but a deflection of approximately the width of the record was the equivalent to a pressure change of $20 \mathrm{~cm}$ of water. The two beats occurred at end expiration at constant intrathoracic pressure. Instantaneous flow is integrated to give stroke volume, the integrator being discharged from the ECG. The isovolumetric and ejection phases of the contractions are indicated. There is an inherent delay of from 2.5 to $5 \mathrm{msec}$ in the flow signal, and this was allowed for in the calculations.

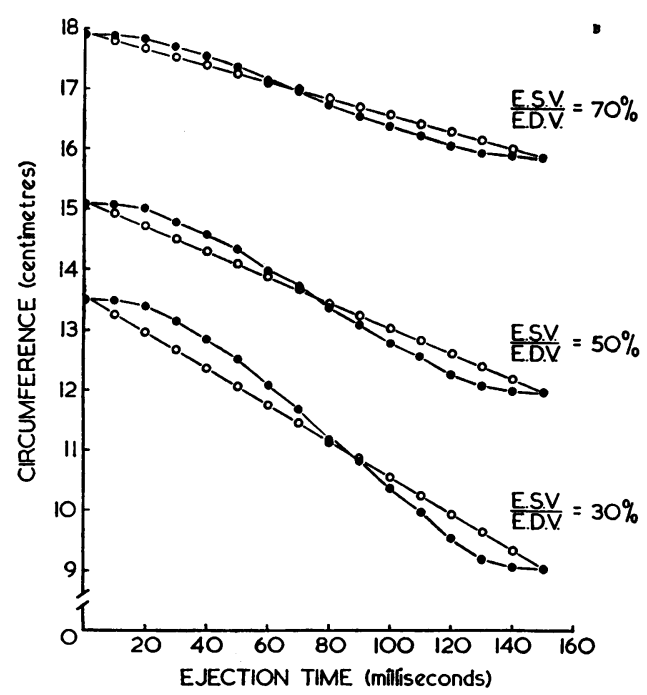

B. RELATIONSHiP BetWeEN CALCULATED CIRCUMFERENCE AND TIME, DURING EJECTION, FOR THREE POSSIBLE ENDDIASTOLIC VOLUMES USING VALUES FOR PRESSURE AND FLOW GIVEN BY BEAT B of Figure 1A. The end-diastolic volumes are those given by end-systolic volume/end-diastolic volume (ESV/EDV) ratios of $30 \%, 50 \%$, and $70 \%$ (see text). Values for the circumference given by an assumed constant rate of circumferential shortening are also shown (open circles).

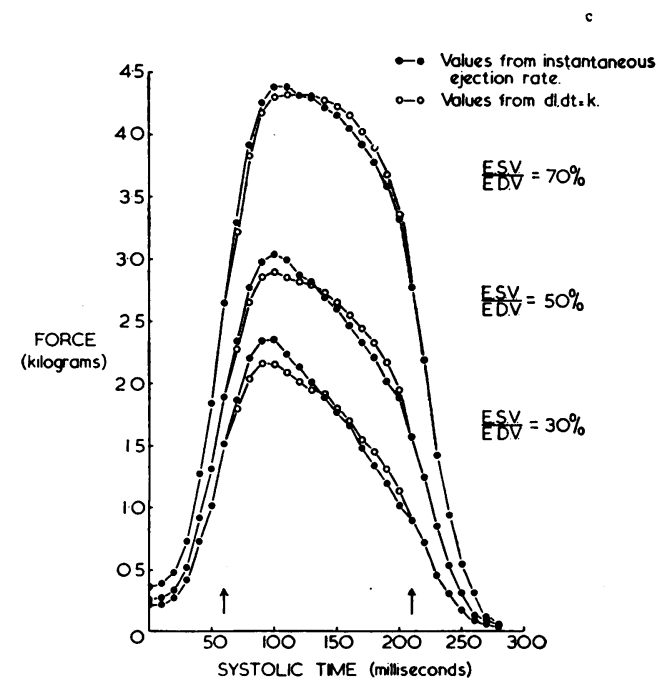

C. Relation between tangential Force, $F_{M}$, AND TIME DURING SYSTOLE FOR VALUES OF PRESSURE AND FLOW GIVEN BY BEAT B OF FIGURE $1 \mathrm{~A}$ AND END-DIASTOLIC VOLUMES GIVEN BY ESV/EDV RATIOS OF 30\%, 50\%, AND $70 \%$ (SEE TEXT). The values for $\mathrm{F}_{\mathbf{M}}$ assuming a constant rate of circumferential shortening $(\mathrm{dl} \cdot \mathrm{dt}=\mathrm{k})$ are shown as open circles. Arrows indicate the beginning and end of the ejection period. Differences between the two sets of values are small. 


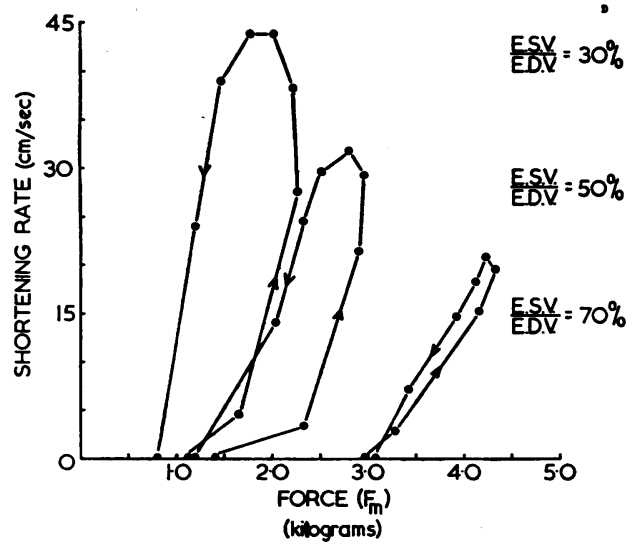

D. Relationship between Shortening RATE AND Fy DURING SYSTOLE FOR VALUES OF PRESSURE AND FLOW GIVEN BY BEAT B OF FiguRE 1A AND END-DIASTOLIC VOLUMES GIVEN BY ESV/EDV RATIOS OF 30\%, 50\%, AND $70 \%$ (SEE TEXT). The loops are counterclockwise with some hysteresis.

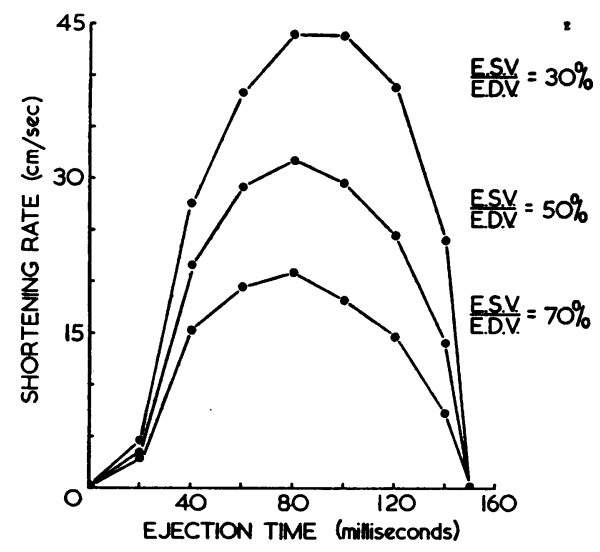

E. RELATIONSHIP BETWEEN SHORTENING RATE AND TIME DURING EJECTION FOR VALUES OF FLOW AND TIME GIVEN BY BEAT B OF FIGURE 1A AND END-DIASTOLIC VOLUMES GIVEN BY ESV/EDV RATIOS OF $30 \%, 50 \%$, AND $70 \%$ (SEE TEXT). The curves are approximately symmetrical with a tendency towards a plateau around the middle of ejection.

ratio at $30 \%$, the mean difference was $-2.5 \%$, and the differences ranged between $-7.5 \%$ and $+0.2 \%$. When the ESV/EDV ratio was $50 \%$, the mean difference was $-1.4 \%$ and the differences ranged between $-0.1 \%$ and $-3.6 \%$. When the ESV/EDV ratio was $70 \%$, the mean difference was $-0.2 \%$ and the differences ranged between $-1.4 \%$ and $+0.5 \%$.

The form of the force-time relationship during systole was consistent in all the experiments. With the onset of ejection there was an early brief rise after which the force fell rapidly during the remainder of the ejection period. In the example shown in Figure $1 \mathrm{C}$ the ejection time was $150 \mathrm{msec}$, and the calculated force fell continuously after the first $40 \mathrm{msec}$, when as Figure 1A shows, the intraventricular pressure is still rising relatively rapidly.

When calculated instantaneous circumferential shortening velocity was plotted against calculated instantaneous force, a counterclockwise loop with some hysteresis was found in all instances. Figure 1D shows some typical examples.

Figure 1E illustrates the relationship between calculated shortening velocity and time during ejection. Shortening velocity varies widely and is clearly not constant, and this is also evident from Figure 1D. It increases gradually until about the middle of ejection and then decreases to form an approximately symmetrical curve. This was seen for values of EDV given by each of the $\mathrm{ESV} / \mathrm{EDV}$ ratios used.

A representative time-concentration curve obtained in a patient with a normal left ventricle is illustrated in Figure 3A. The concentrations de-

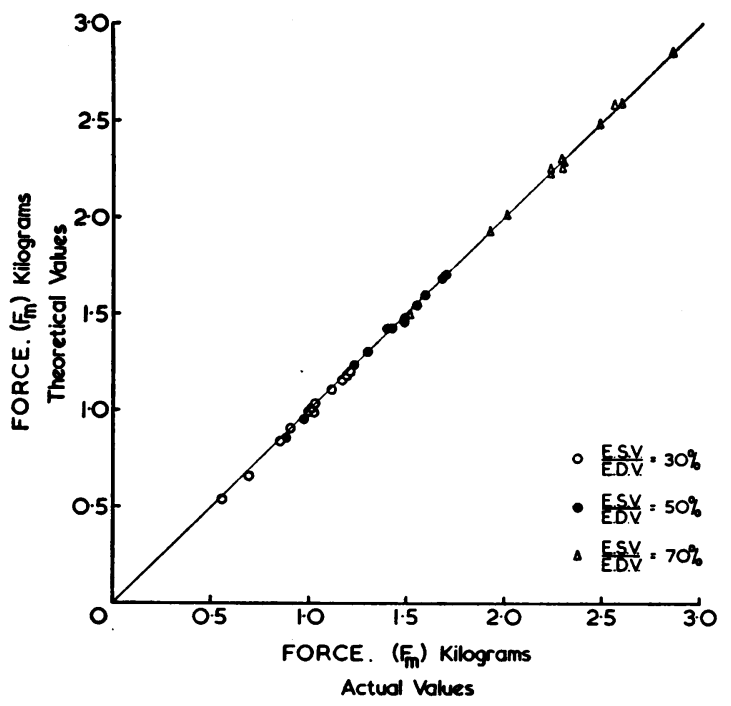

Fig. 2. Relationship between Mean tangential FORCE, $\bar{F}_{\mathbf{x}}$, CALCULATED USING THE CHANGE IN VENTRICULAR VOLUME OBTAINED FROM THE INSTANTANEOUS EJECTION RATE, AND USING AN ASSUMED CONSTANT RATE OF CHANGE OF CIRCUMFERENCE (SEE TEXT). The values plotted are those obtained in all dogs for ESV/EDV ratios of $30 \%$, $50 \%$, and $70 \%$. The actual values refer to those obtained from the instantaneous ejection rate. The line of identity is shown. 
cline in a stepwise manner at each beat. In Fig- Figure 4A shows a curve obtained during a study ure $3 \mathrm{~B}$ the average concentrations at each step of a patient with a cardiomyopathy, who was in are plotted semilogarithmically and are seen to de- left ventricular failure with a relatively high carcline exponentially. In all the curves included in diac output. The indicator washes out of the venthis study a similar exponential decline was found. tricle slowly (Figure 4B) taking 22 beats as
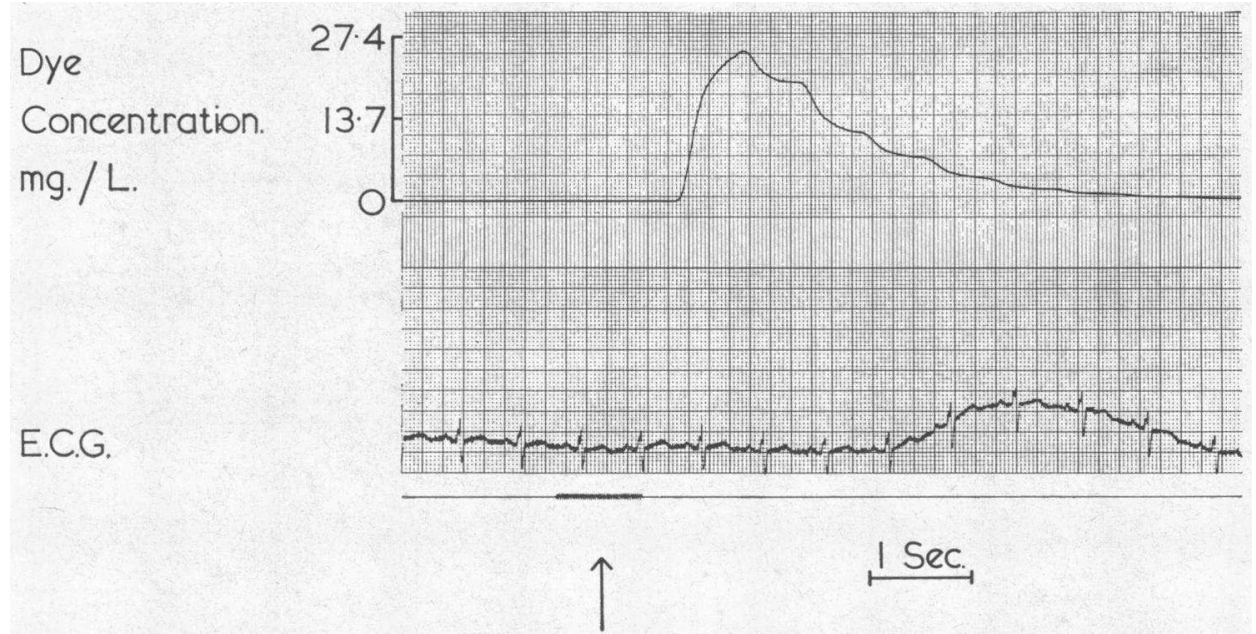

Fig. 3 A. Curve obtained by aortic sampling after Rapid injection of 4 mL containing 5 MG OF CARDIOGREEN INTO A NORMAL LEFT VENTRICLE. The time of injection is marked, but as this was done manually the duration of the injection is not represented accurately.

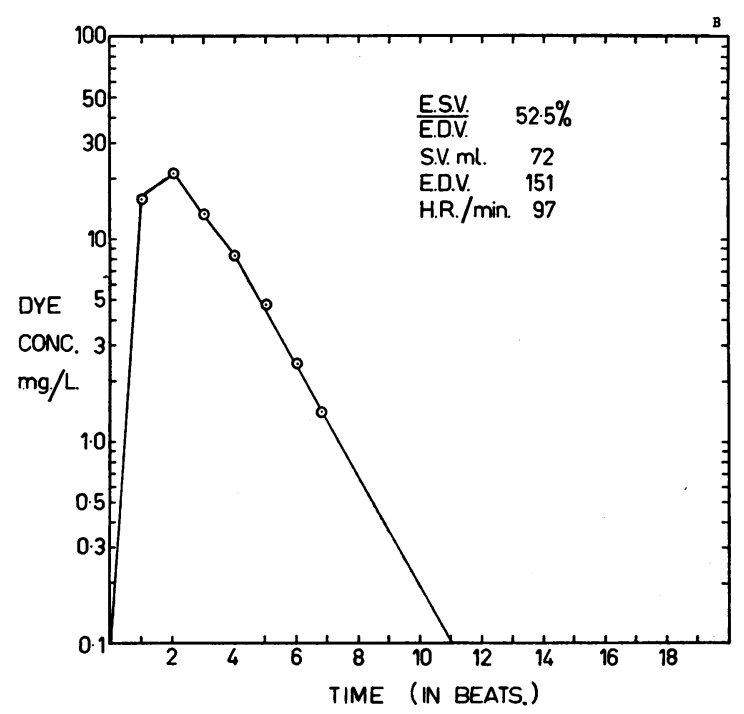

B. Semilogarithmic plot of the concentration of CARDIOGREeN IN THE BLOOD EJECTED AT EACH BEAT. Data obtained from the curve shown in Figure 3A. The concentrations decline exponentially. S.V. = stroke volume; H.R. = heart rate. 


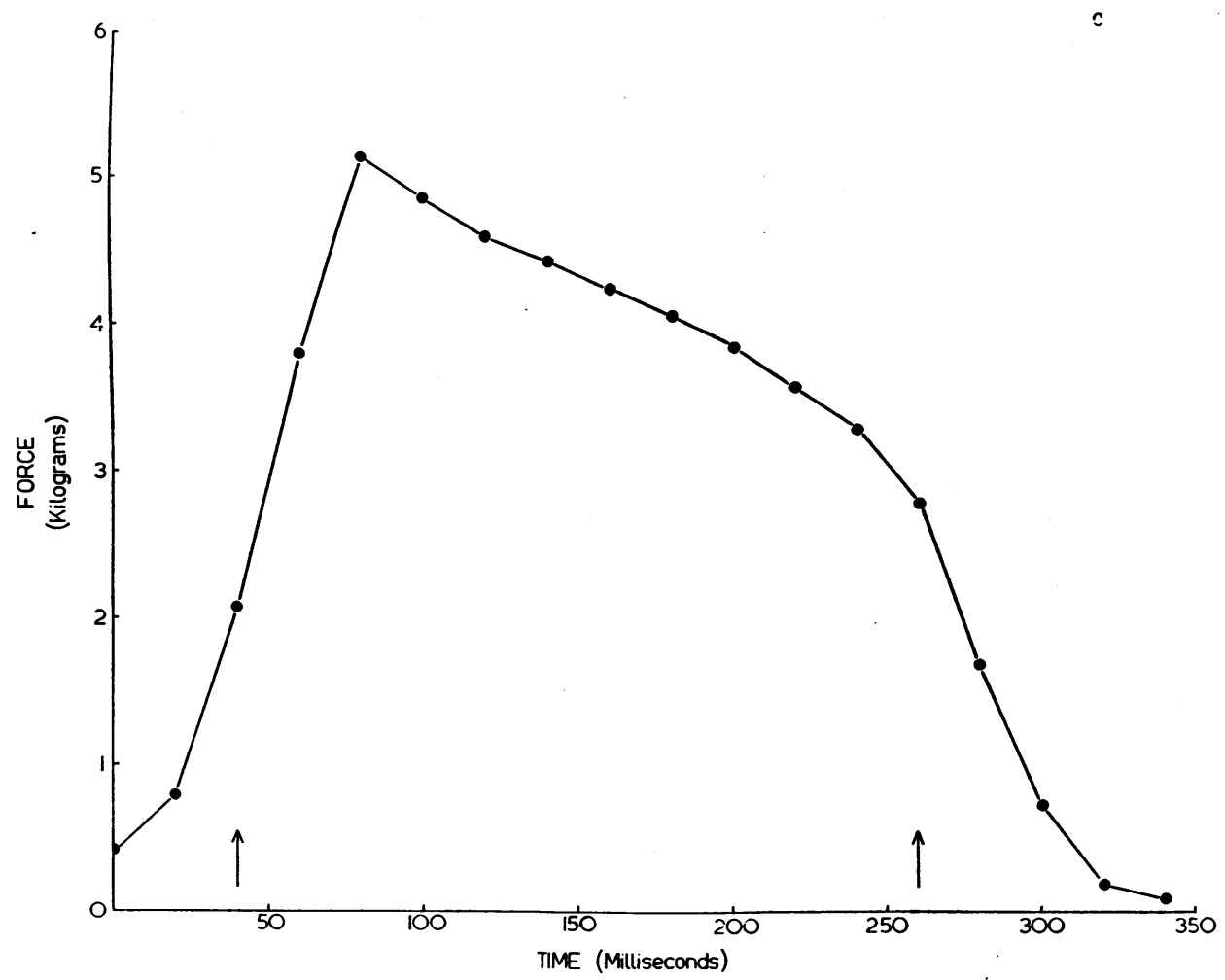

C. RELATION BETWEen TANGENTIAL FORCE, Fu, AND TIME THROUGHOUT SYSTOLE IN THE PATIENT of CURVE 3A. Arrows indicate the beginning and end of ejection. Forty msec after the onset of ejection $F_{M}$ begins to fall and continues to do so throughout the rest of the contraction.

against 11 beats in the normal patient of Figure $3 \mathrm{~B}$, and the values for EDV, ESV/EDV, and enddiastolic pressure are appreciably elevated.

The values for ESV/EDV, EDV, and other relevant data obtained in the patients studied are shown in Table I. The normal patients are arranged in order of age, and there is a general trend towards an increase in ESV/EDV, and therefore a decrease in the proportion of the EDV ejected, in the older patients. The two youngest, both of whom were athletes, had the slowest resting heart rates, the largest stroke volumes, the smallest ratios of ESV/EDV, and the largest resting end-diastolic volumes related to body surface area. The smallest ratios of ESV/EDV and the smallest enddiastolic volumes related to body surface area were found in two patients with mitral stenosis. On the whole the EDV and ESV/EDV were large in the patients with definite left ventricular abnormality, markedly so in those with other evidence of left ventricular failure (Cases 18 to 21).

The values for $\bar{F}_{M}$ and circumferential shortening rate $(\mathrm{dl} \cdot \mathrm{dt})$ are also shown in Table I. In the normal group there appears to be a tendency for a given $\bar{F}_{\mathbf{M}}$ to be associated with a slower shortening rate in the older patients even with the differences to be expected with variations in the size of the patients and presumably in the size of the left ventricular muscle mass considered. In two of the patients with mitral stenosis, those with the smallest hearts, $\overline{\mathrm{F}}_{\mathbf{M}}$ was accordingly small, and $\mathrm{dl} \cdot \mathrm{dt}$ was the highest of the whole series. But striking differences are evident when the values found in the two previous groups are compared with those found for hearts in which the left ventricle was definitely abnormal. $\bar{F}_{\mathbf{M}}$ is appreciably increased (normal patients: mean $3.41 \mathrm{~kg}$, range 1.84 to $4.5 \mathrm{~kg}$; abnormal patients : mean $6.06 \mathrm{~kg}$, range 4.88 to $7.35 \mathrm{~kg}$ ). The circumferential shortening rate is considerably decreased in four, whereas it is reasonably maintained in the two patients with aortic stenosis (Cases 15 and 16), who still remained compensated and in Case 19, who had an unusual type of cardiomyopathy (see below).

The form of the force-time relationship during 
ejection in the normal subjects was similar to that seen in the dogs (Figures $1 \mathrm{C}$ and $3 \mathrm{C}$ ). There was an early brief rise after which the force fell steeply and continuously during the remainder of systole. This was not so in the patients in left ventricular failure in whom the contraction tended to be more isotonic. From its maximum in the early ejection period the force fell much more slowly (Figure 4C).

The external work produced in these contractions is shown in Table II, together with values for the load or mean force opposed $\left(\overline{\mathrm{F}}_{\mathrm{T}}\right)$ during the contraction. Expressed as a ratio, external work/load varied between 1.07 and 0.58 in the

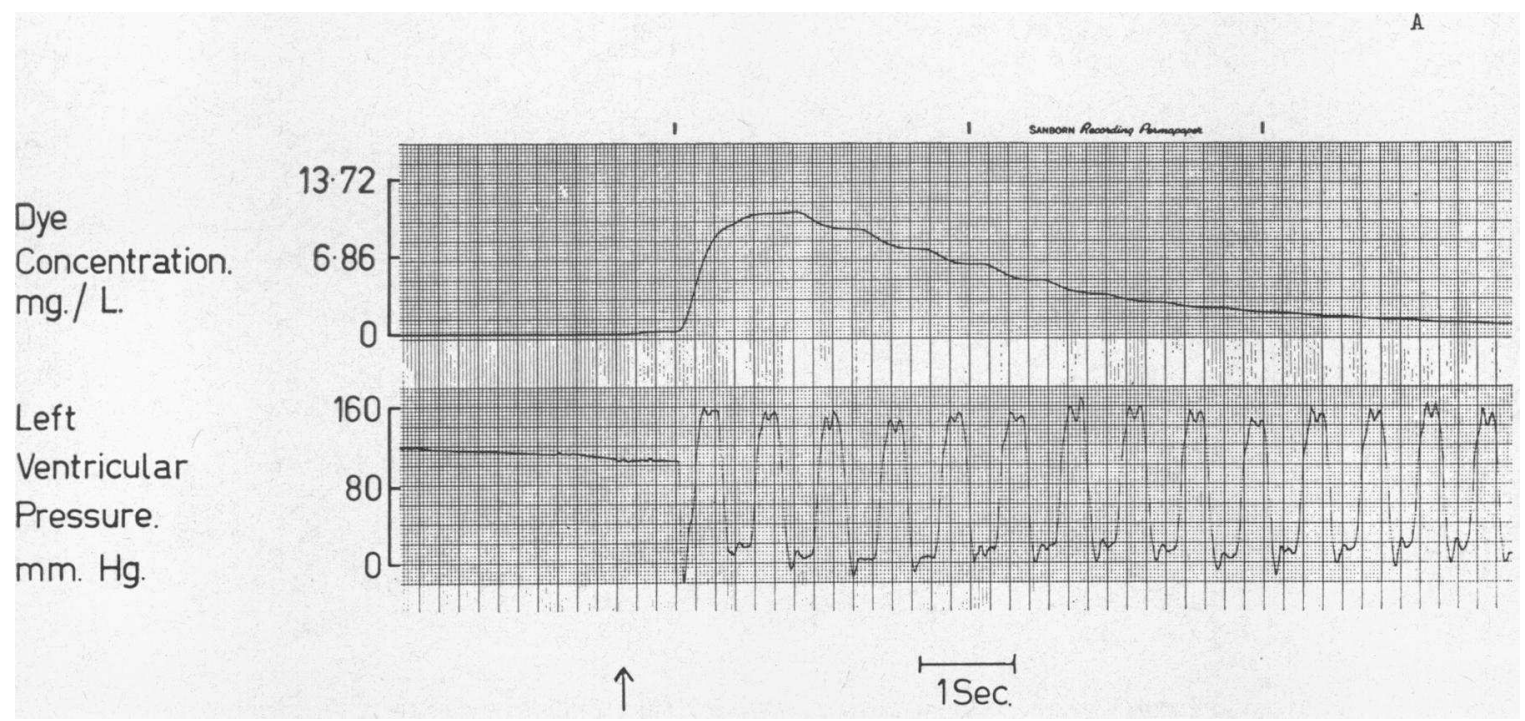

Fig. 4 A. Curve from a patient in left ventricular fallure. The time of injection is indicated. The dye is washed out of the ventricle relatively slowly. The end-diastolic pressure is elevated.

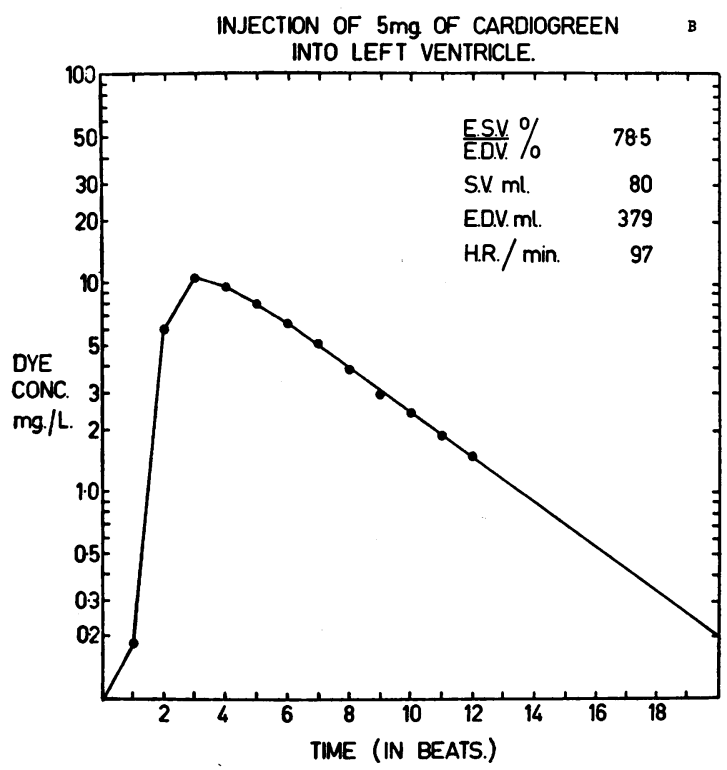

B. Semilogarithmic plot of concentrations of CARDIOGREEN AT EACH BEAT. Data from the curve shown in Figure 4A. The decline is exponential after the third beat. 


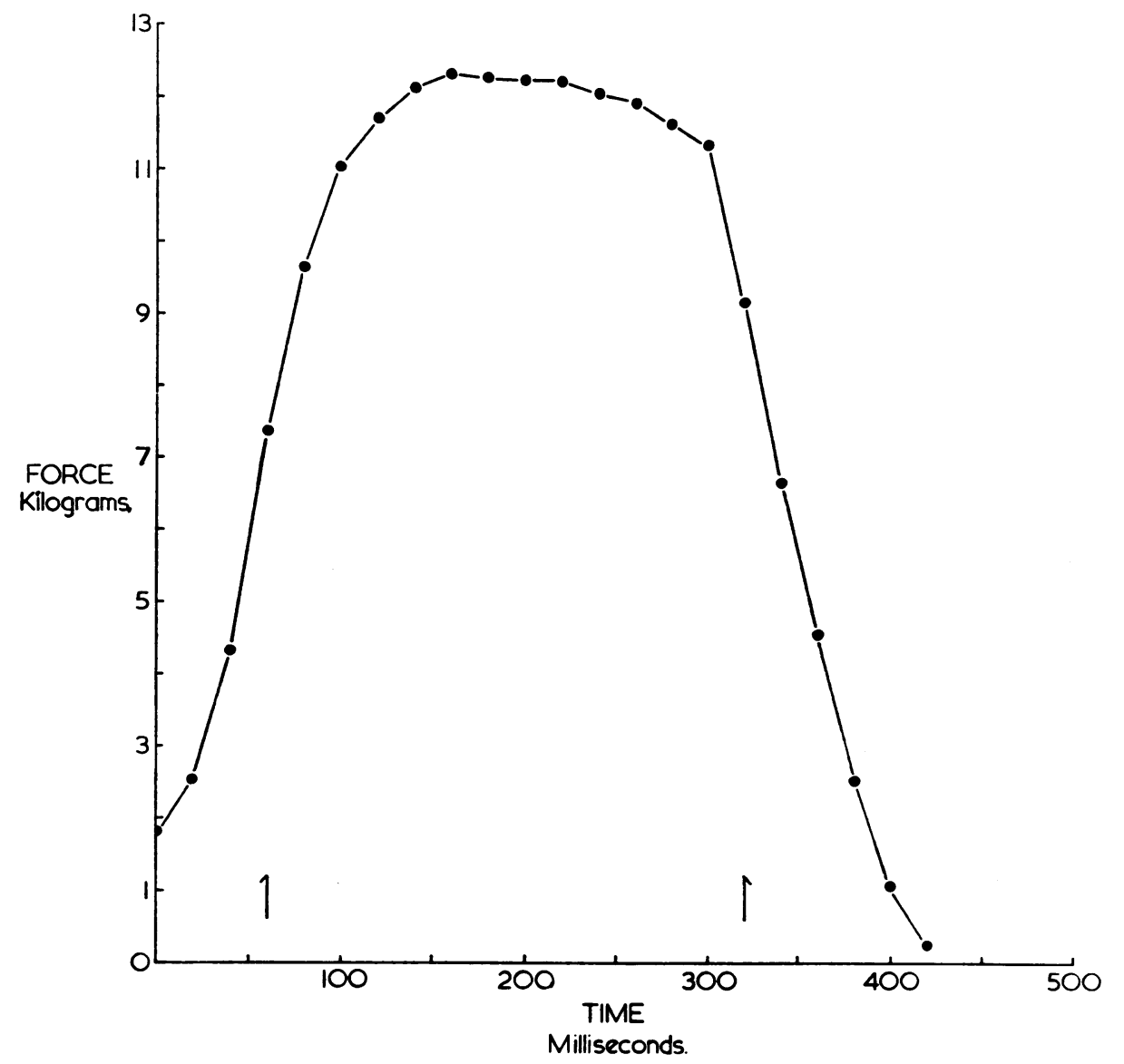

C. Relation BETWEen tangential FORCE, $F_{\mathbf{m}}$, AND tIME THROUGHOUT SYSTOLE IN THE PATIENT of CURVE 4A. Arrows indicate the beginning and end of ejection. In contrast to the contraction shown in Figure $3 \mathrm{C}$, this contraction is almost isotonic.

normal subjects. The patients with mitral stenosis gave values either within or above this range, whereas in the group with definite left ventricular abnormality, there was a general tendency for this ratio to be depressed (mean 0.50 , range 0.82 to 0.27 ). When the factor of heart rate was considered and the power transferred to the systemic circulation related to the average force that the left ventricle opposes in each second, similar differences emerged (Table II, C/D). The differences between the normal and abnormal subjects are definite, and in one patient (Case 15), in whom the ratio external work/load is in the normal range, this second ratio $(C / D)$ is below the range of values found in normal subjects. The values for the patients with mitral stenosis were all above the lower limit of the range found in normals.

\section{Discussion}

Ventricular volume. Calculations of the forces opposing left ventricular ejection are critically dependent on the accuracy of the volume measurements. The validity of the present method for measuring left ventricular volume in man was investigated in a previous study (15), and the findings suggested that the results obtained by this method are accurate in man. The values for $\mathrm{ESV} / \mathrm{EDV}$ found with the present system in normal subjects (mean 54\%, range 46 to $62 \%$, eight subjects) were the same as those recently reported by Gorlin and his associates (17) using thermodilution (mean 56\%, range 49 to $63 \%$, seven subjects). Values of roughly the same order were also found by Folse and Braunwald (isotope dilution) (18) and Bristow and his associ- 
D. E. L. WILCKEN

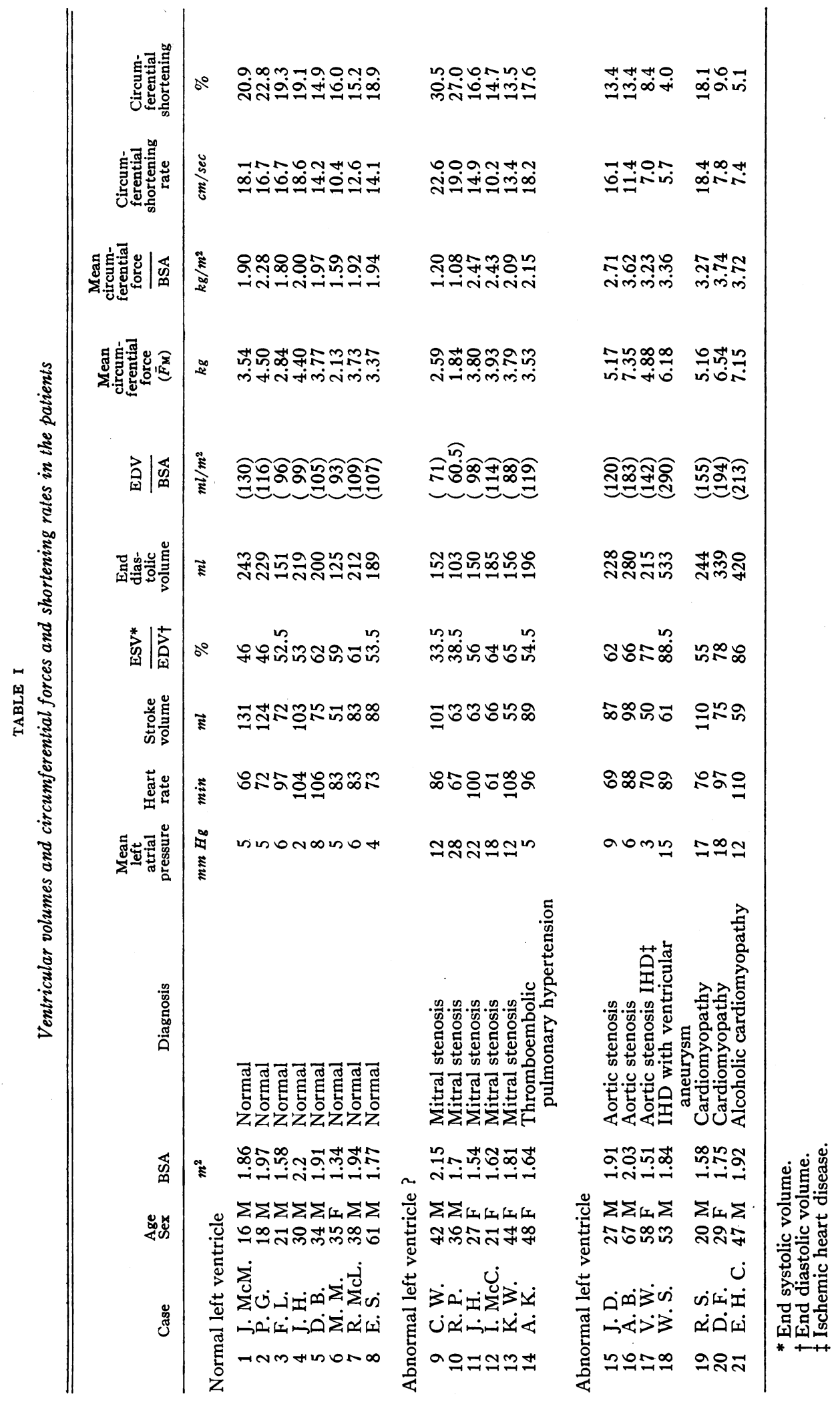


TABLE II

Relationship between external work and mean load per beat, and between power and load averaged over each second

\begin{tabular}{|c|c|c|c|c|c|c|c|}
\hline Case & $\begin{array}{c}\text { Heart } \\
\text { rate }\end{array}$ & $\begin{array}{l}\text { A } \\
\text { Work per } \\
\text { contrac- } \\
\text { tion }\end{array}$ & $\begin{array}{c}\text { B } \\
\text { Mean force } \\
\text { opposed } \\
\text { during } \\
\text { contrac- } \\
\text { tion }\end{array}$ & $\underset{\text { Power }}{\mathrm{C}}$ & $\begin{array}{c}\mathrm{D} \\
\text { Mean force } \\
\text { opposed }\end{array}$ & $\frac{\mathrm{A}}{\mathrm{B}}$ & $\frac{\mathrm{C}}{\mathrm{D}}$ \\
\hline & $\min$ & $k g-c m$ & kg & $\mathrm{kg}-\mathrm{cm} / \mathrm{sec}$ & kg & & \\
\hline \multicolumn{8}{|c|}{ Normal left ventricle } \\
\hline $\begin{array}{l}1 \\
2 \\
3 \\
4 \\
5 \\
6 \\
7 \\
8\end{array}$ & $\begin{array}{r}66 \\
72 \\
97 \\
104 \\
106 \\
83 \\
83 \\
73\end{array}$ & $\begin{array}{r}15.2 \\
17.9 \\
9.3 \\
15.4 \\
9.3 \\
6.1 \\
10.3 \\
13.3\end{array}$ & $\begin{array}{l}14.1 \\
18.0 \\
11.3 \\
17.6 \\
15.1 \\
10.5 \\
14.9 \\
13.5\end{array}$ & $\begin{array}{r}16.7 \\
21.4 \\
15.0 \\
26.6 \\
16.5 \\
9.2 \\
14.0 \\
16.2\end{array}$ & $\begin{array}{r}7.5 \\
9.5 \\
6.6 \\
11.6 \\
8.5 \\
7.6 \\
9.8 \\
8.5\end{array}$ & $\begin{array}{l}1.07 \\
0.99 \\
0.88 \\
0.87 \\
0.61 \\
0.58 \\
0.69 \\
0.99\end{array}$ & $\begin{array}{l}2.23 \\
2.25 \\
2.29 \\
2.30 \\
1.94 \\
1.20 \\
1.40 \\
1.90\end{array}$ \\
\hline \multicolumn{8}{|c|}{ Abnormal left ventricle } \\
\hline $\begin{array}{r}9 \\
10 \\
11 \\
12 \\
13 \\
14\end{array}$ & $\begin{array}{r}86 \\
67 \\
100 \\
61 \\
108 \\
96\end{array}$ & $\begin{array}{r}15.7 \\
8.4 \\
8.7 \\
10.4 \\
7.8 \\
10.8\end{array}$ & $\begin{array}{r}10.4 \\
7.4 \\
14.4 \\
15.7 \\
15.2 \\
14.2\end{array}$ & $\begin{array}{r}22.5 \\
9.4 \\
14.5 \\
10.5 \\
14.1 \\
18.0\end{array}$ & $\begin{array}{l}7.1 \\
4.3 \\
7.7 \\
8.7 \\
9.9 \\
7.5\end{array}$ & $\begin{array}{l}1.51 \\
1.15 \\
0.60 \\
0.66 \\
0.53 \\
0.76\end{array}$ & $\begin{array}{l}3.16 \\
2.21 \\
1.89 \\
1.22 \\
1.42 \\
2.37\end{array}$ \\
\hline \multicolumn{8}{|c|}{ Abnormal left ventricle } \\
\hline $\begin{array}{l}15 \\
16 \\
17 \\
18 \\
19 \\
20 \\
21\end{array}$ & $\begin{array}{r}69 \\
88 \\
70 \\
89 \\
76 \\
97 \\
110\end{array}$ & $\begin{array}{r}13.4 \\
19.4 \\
8.3 \\
6.7 \\
16.9 \\
9.3 \\
8.5\end{array}$ & $\begin{array}{l}20.7 \\
29.4 \\
19.5 \\
24.7 \\
20.6 \\
26.1 \\
28.6\end{array}$ & $\begin{array}{r}15.4 \\
29.6 \\
9.6 \\
10.0 \\
21.4 \\
15.0 \\
15.6\end{array}$ & $\begin{array}{l}15.4 \\
21.0 \\
10.9 \\
17.6 \\
12.5 \\
17.8 \\
21.0\end{array}$ & $\begin{array}{l}0.65 \\
0.66 \\
0.42 \\
0.27 \\
0.82 \\
0.35 \\
0.30\end{array}$ & $\begin{array}{l}1.00 \\
1.41 \\
0.88 \\
0.57 \\
1.70 \\
0.84 \\
0.74\end{array}$ \\
\hline
\end{tabular}

ates (thermodilution) (19). The shorter timeconstant of the thermodilution technique is an advantage, but the similar values obtained indicate that at normal heart rates the time-constant of the present method is adequate for studies in man. On the other hand, stroke volume and ESV/EDV, and therefore EDV, are obtained from the same curve with the method used in this study rather than from consecutive thermodilution and dye dilution curves. This tends to minimize errors. Angiographic methods for measuring left ventricular volumes in man have given resting values for EDV and ESV/EDV in normal adults lower than those found in the present investigation (20-22), but there are indications that at least some of the values obtained by the former method are too low (17). At present these differences are unresolved.

The five patients with mitral stenosis, as a group, had considerably smaller ventricular volumes than the normal patients. This becomes more apparent when the EDV per square meter of body surface area is compared with that of normal patients, measured at approximately the same heart rates (Table I). The EDV was smaller in four of the five patients and in the normal range in the other (Case 11). The three smallest values in the whole series for end-diastolic volume related to body surface area occurred in patients with mitral stenosis. A small left ventricular volume in pure rheumatic mitral stenosis was an expected finding, since it is a matter of clinical observation that the left ventricle, as seen radiologically and at thoracotomy, is small in patients with mitral stenosis. However, the data further demonstrate that one way in which the output is maintained in mitral stenosis is by greater emptying of the left ventricle. This is in accordance with an inverse relationship between the force generated and velocity and extent of muscle shortening. It is well shown in two patients with severe mitral stenosis (Cases 9 and 10) in whom the left ventricle was very small and the values for ESV/EDV (33.5\% and $38 \%$ ) and load (mean circumferential force per $\mathrm{m}^{2}$ of BSA of 1.20 and 1.08 kilograms) were the lowest of the series. They also had the fastest average shortening rates and the greatest percentage of shortening. These findings for ESV/EDV and EDV differ from those of Bristow and his 
associates (19) and Gorlin and his associates (17) in patients with severe mitral stenosis. They found values for EDV and ESV/EDV in the normal or increased range using thermodilution. These differences may reflect variations in the severity of myocardial rheumatic involvement, as it would be anticipated that a normal or increased ESV/EDV and EDV in severe isolated mitral stenosis could be due to impaired muscle function.

Load and circumferential shortening rate. The calculated forces represent approximations only of the forces opposing shortening, as the assumptions underlying the method of calculation are not completely fulfilled. The left ventricle is not spherical and in end diastole normally resembles more a prolate spheroid (23) or a truncated cone $(24,25)$. It does, however, tend to become more spherical as it fails and dilates, and during the period of isovolumetric contraction it becomes more spherical in both normal and abnormal hearts (24, 25 ). Because of these changes in shape it is incorrect to assume that no shortening occurs during the period of isovolumetric contraction, but such shortening as does occur is almost entirely in the long axis of the ventricle and represents only a small proportion of the total shortening. In general, errors in the calculated $\overline{\mathrm{F}}_{\mathbf{T}}$ and $\overline{\mathrm{F}}_{\mathbf{M}}$ due to this factor should be small, as pressure is the variable in which large changes are occurring, and this can be measured reasonably accurately. Furthermore, the period as a whole is short and, as can be seen from Figures 1B, 3B, and 4B, the mean force opposed during this period is considerably less than the mean force opposing the whole contraction. For similar reasons, the errors introduced during the period from the closure of the aortic valve until the intraventricular pressure falls to its lowest level will be relatively small.

The forces are largest during the ejection period. The errors introduced by assuming a constant rate of ventricular muscle shortening in the calculation of the load were found to be negligible for ventricular volumes and $\mathrm{ESV} / \mathrm{EDV}$ ratios in the physiological range. Even smaller errors would be expected if the ratio and EDV were larger than the range studied, for then the volume change during ejection would be smaller in relation to the EDV and ESV.

The form of the aortic flow curve is determined by the manner in which the left ventricular muscle shortens. In dogs the aortic flow curve has the same general form under widely differing conditions. When large changes in load were produced in conscious dogs, resulting in appreciable changes in stroke volume and evidence of changes in levels of neurohumoral stimulation, the flow curve, although altered, retained the same form (6). During marked sinus arrhythmia variations in stroke volume of up to $50 \%$ occurred in consecutive beats in resting or sleeping dogs (26). These stroke volume changes were accompanied by changes in the ejection time, in the peak and mean aortic velocity, and in the acceleration of the ejected blood such that the curves tended to retain the same shape (26). These findings indicate that the ejection pattern, on which the present findings depend, tends to be relatively constant and suggests that the present findings are applicable generally in the dog.

Instantaneous flow curves recorded at the root of the aorta of patients with both normal and abnormal left ventricles have the same general form as those found in dogs (27-29). Although the term in the calculation of load that depends on ventricular volume is normally much larger in man than that in the dog, as the ejection pattern is the same, the errors introduced should not be any larger. For these reasons it is very likely that the conclusions drawn from the dog experiments apply also to man. It seems reasonable to conclude that relatively accurate values for the forces opposing normal and abnormal left ventricular contraction in man may be calculated by using the method proposed.

Evidence has been provided by Hefner, Sheffield, Cobbs, and Klip, with direct force measurements in dogs (30), that a spherical model describes closely the behavior of the rim of muscle encircling the left ventricle parallel to and just below the atrioventricular groove, in terms of the forces it generates and opposes. These findings encourage the view that $\bar{F}_{\mathbf{M}}$ as calculated in the present study corresponds closely to the actual net tangential force developed in the ventricular muscle in the plane under consideration. The force $F_{M}$ d.pends only on the intraventricular pressure and the cross sectional area of the cavity and is independent of the size and shape of the remainder of the ventricle. From all these considerations it seems likely that $\bar{F}_{\mathbf{M}}$ represents more accurately the mean force generated by the muscle in the plane being considered than does $\overline{\mathrm{F}}_{\mathbf{T}}$ the load op- 
posing total left ventricular shortening. It is probable though that $\overline{\mathrm{F}}_{\mathrm{T}}$ itself is not greatly in error. Dodge, Sandler, Ballew, and Lord (23) showed angiographically that the left ventricle in man closely resembles a prolate spheroid having a major: minor axis of approximately $2: 1$. Differences in the values obtained for a calculated force when this and a spherical model are used have been shown to be small (17).

As far as the author is aware, there are no other values available in the literature for $\overline{\mathrm{F}}_{\mathbf{T}}$ and $\overline{\mathrm{F}}_{\mathbf{M}}$ in man, with the exception of a recent report by Gorlin and his associates (17) published after the work contained in this paper was completed. Gorlin and his associates (17) presented data for the mean systolic force in man. They estimated a mean systolic radius from the sum of the endsystolic radius and one quarter of the difference between the end-diastolic and end-systolic radius. This value and the mean systolic pressure of the left ventricle were used in the calculation of mean force. In the present study an integrated mean force was calculated.

The values obtained by Gorlin and his associates (17) in seven patients with normal hearts were consistently higher than those represented here. The calculated mean force obtained was $22 \%$ higher than in the present study and $23 \%$ higher when the force was expressed per square meter of body surface area. As ventricular volumes and heart rates were similar in the two studies, and a systematic pressure difference seems unlikely, it seems probable that the difference is due to the method used to calculate the force.

The present studies provide data for the form of the force-time relation during systole in man (Figure $3 \mathrm{C}$ ). In normal resting subjects it was similar to that found by Hefner and his associates in anesthetized dogs using direct measurements (30). A similar relation was found under physiological conditions in the present dog experiments for the wide range of values for EDV and ESV/ EDV used. A fall in load must occur towards the end of normal systole, after the peak pressure has been reached, since ventricular volume is still decreasing; accurate intraventricular pressure measurements show the peak pressure to occur normally about two-thirds of the way through the ejection period (Figure 1A). The present studies show that the load actually begins to decrease during the first third of the ejection period, at a time when the pressure is still rising rapidly (Figures $1 \mathrm{C}$ and $3 \mathrm{C}$ ).

The loops describing the relationship between instantaneous force and instantaneous shortening velocity (Figure 1D) were similar to those depicted recently by Levine and Britman (31), and the maximal force occurred at approximately the same point on the loop; but it is not possible to compare the values obtained.

The calculated shortening rate changed considerably over the whole ejection period, but tended to reach a plateau in mid systole (Figure 1E). Records of direct measurements of movements of the left ventricular circumference and diameter in dogs $(32,33)$ reveal that in these too there is a period, about half the length of ejection, in which shortening rate does not vary greatly. This is a point that has not been commented upon previously.

In the patients there is a trend towards an inverse relationship between the average shortening rate and load (Table I), which is improved when the data are related to body surface area. Nevertheless it is not possible to draw any conclusions about this relationship in view of the almost certain differences in inotropic state between the patients, the variations in wall thickness and initial volume, and the fact that in the majority of cases the muscle was pathological.

Load and external work and power. The variations in force with time found in the patients and calculated in the dogs permit some deductions about the external work performed during left ventricular contraction. Hill $(34,35)$ has pointed out that to obtain maximal work from a contraction, the load must be adjusted so that at each instantaneous length during shortening the muscle is just, and only just, able to overcome it. As maximal tension is known to develop early in a skeletal or cardiac muscle twitch, and thereafter progressively and more slowly to decline, maximal external work can only be obtained if there is an early rapid increase in load followed by a progressive decline to match precisely the early rise and slower decline in tension. These conditions have been reproduced experimentally for skeletal muscle $(2,35)$.

The data presented in this paper show that this pattern of loading is approached in the normal left ventricle in that the load progressively declines as the contraction proceeds. But how closely the de- 
cline in load is "matched" to the decline in maximal possible tension is not revealed by this study. Matching cannot be perfect because there are isovolumetric periods, but it seems probable, nonetheless, that it is fairly close; in an earlier study in normal conscious dogs any sudden change in load during a steady state, either an increase or decrease, always resulted in a fall in the amount of external work done in the subsequent beat (6). The present study also demonstrates that in a failing left ventricle contractions are nearly isotonic (Figure 4C). It is impossible to choose a constant load that remains an optimum at all lengths during shortening (2). Because of this the contractions of a failing left ventricle must do less external work than would be the case if the load could be modified so as to decline with the decline in tension.

In studying the relationship between the force opposed and the external work performed, units of measurement were chosen that would allow the two to be compared conveniently. Some conclusions about the efficiency (external work/energy input) of the contractions may be drawn from these data. Britman and Levine (36) recently found that contractile element work and myocardial oxygen consumption were highly correlated in the dog, much more so than was oxygen consumption with other indexes currently used. Contractile element work takes account of the two mechanical effects of the contractile effort, the force generated (by lengthening of the series elastic component) and fiber shortening. The former is the force developed, and the latter determines the amount of external work done. The data of Britman and Levine (36) therefore provide evidence that the oxygen consumption of the left ventricle is closely related to the energy expended by the contractile component in producing the two mechanical effects being measured. If these data are applicable to man, a fall in the ratio of external work to force developed, resulting from a rise in the force developed, would indicate a less efficient contraction. When the end-diastolic pressure is normal this ratio is determined largely by the relationship between stroke volume and mean systolic ventricular volume. This is not necessarily so when the end-diastolic pressure is raised, as it may be with or without an increase in enddiastolic volume depending on the distensibility of the ventricle.
As Table II shows, the ratio of external work to load found in the normal subjects varied between 1.07 and 0.58 (mean .83). It seems possible that a variety of circumstances including age and physical fitness could affect these ratios, and it might be relevant that Cases 1 to 4 and Case 8, who had the highest resting ratios, had nonsedentary occupations and took frequent exercise. This was not so in Cases 5 to 7 in whom the ratios were lower. It is however doubtful whether Patients 5,6 , and 7 are completely normal although these somewhat depressed ratios of work/load provide the only available direct evidence for left ventricular abnormality. Patient 5 had had two substantial pulmonary emboli, Patient 6 had had an oophorectomy several years previously, complained of atypical chest pain, and had an elevated serum cholesterol, and Patient 7 had multiple small pulmonary emboli, but had no evidence of pulmonary hypertension or arterial desaturation. Those patients with unequivocally abnormal left ventricles showed ratios that were either abnormally low or in the lower normal range (with one exception, Case 19). The two patients with aortic stenosis (Cases 15 and 16) had ratios in the low normal range. This could be due to the development of sufficient functioning hypertrophy to maintain work-load and efficiency-load relationships somewhere near normal even though, as both work and load are increased, over-all left ventricular energy expenditure was presumably increased. This might also be so in Case 19, who had an unusual form of cardiomyopathy with extreme left ventricular hypertrophy, a high resting cardiac output, and some systemic hypertension, and appeared to be similar to the patients with idiopathic myocardial hypertrophy described by Braunwald and Aygen (37).

On the other hand; due to a decrease in load (related to body surface area) the ratio of external work to load was considerably above the normal range in one patient with mitral stenosis (Case 9). The significance of this is not at present apparent.

The force averaged over each second takes account of both the frequency and the duration of the contraction. It is possible that a consideration of this and the rate of doing external work (external power) may give a clearer indication of the way in which the left ventricle utilizes the energy available to it. The separation between the normals and abnormals is again clear-cut. In two 
patients with abnormal left ventricles (Case 16, who had compensated aortic stenosis, and Case 19 with the unusual cardiomyopathy) the values were above the lower limit of the range of values found in the normals. The values were within the "normal" range in all the patients with mitral stenosis, in whom there was a wide range of values. Further data are required before the significance of this can be established, but it seems likely that in one patient with mitral stenosis (Case 13) in whom the left ventricle was small the low ratios of external power/load averaged over a second and of work/load indicate impaired muscle function.

In heart failure the abnormality is not usually of energy production by the heart but the energy utilization $(38,39)$, and the mechanical disadvantage of cardiac enlargement has been repeatedly emphasized in theoretical discussions $(8,9,40)$. By quantitating the forces opposed and external work performed during contraction the present studies demonstrate this for the left ventricle in man, in that they show that large amounts of energy must be spent in generating and opposing forces that are increased greatly above normal, in order to transfer a normal or reduced amount of power to the systemic circulation. But in addition these data permit the severity of the mechanical abnormality to be estimated, and the methods proposed may prove sensitive in determining lesser degrees of impaired heart muscle function.

\section{Summary}

1) Methods for calculating the forces opposing left ventricular ejection were studied in six conscious dogs. It was concluded from these experiments that force-time relationships during left ventricular systole could be studied with reasonable accuracy without knowing the instantaneous aortic flow rate if the end-diastolic volume, the intraventricular pressure, and the stroke volume are measured and a constant rate of fiber shortening is assumed. Although fiber shortening rate was not constant, the errors introduced by assuming a constant rate were found to be small. Evidence for the applicability of these data to normal and abnormal human hearts is discussed.

2) Based on these findings, instantaneous force and the integrated mean force opposing left ventricular ejection were calculated in 21 patients, using left ventricular volume and pressure measurements.
3) The effects of the variations in force during contraction on the external work performed were considered. The data were consistent with the load varying in such a manner as to permit the normal left ventricle to perform nearly maximal external work during contraction. This was not the case in patients in heart failure. In these the contractions tended to be isotonic.

4) In eight patients with normal left ventricles, the mean force acting tangentially to the circumference varied between 1.59 and 2.28 (mean 1.93) $\mathrm{kg}$ per square meter of body surface area. Patients with mitral stenosis had small left ventricular volumes, and the forces opposing ejection were less. Large forces were found in a group of patients with abnormal left ventricles.

5) External work and power were related to the forces opposed. Values obtained in the normal patients and in those with mitral stenosis tended to fall within the same range. In the patients with abnormal left ventricles the values tended to be reduced. The implications of these findings are discussed.

\section{Acknowledgments}

It is a pleasure to record the thanks due to Dr. R. F. Thew and Sister J. Purchas for help with the cardiac catheterizations and to Miss S. Pickering and Miss R. Robinson for technical assistance and for the illustrations. Two of the dog experiments included in the study were performed while the author was working in the Cardiovascular Research Institute of the University of California (U. S. Public Health Service grant H.E.-06285), and the help of Drs. A. A. Charlier and P. Sleight with those experiments is gratefully acknowledged.

\section{References}

1. Wilcken, D. E. L. Forces opposing left ventricular ejection. Proc. Aust. physiol. Soc. 1965, 7, 42.

2. Hill, A. V. Mechanical efficiency of frog's muscle Proc. roy. Soc. B 1939, 127, 434.

3. Abbott, B. C., and W. F. H. M. Mommaerts. A study of inotropic mechanisms in the papillary muscle preparation. J. gen. Physiol. 1959, 42, 533.

4. Sonnenblick, E. H. Force-velocity relations in mammalian heart muscle. Amer. J. Physiol. 1962, 202, 931.

5. Sonnenblick, E. H., and S. E. Downing. Afterload as a primary determinant of ventricular performance. Amer. J. Physiol. 1963, 204, 604.

6. Wilcken, D. E. L., A. A. Charlier, J. I. E. Hoffman, and A. Guz. Effects of alterations in aortic impedance on the performance of the ventricles. Circulat. Res. 1964, 14, 283.

7. Hales, S. Haemostatics. London, Innys and Manby, 1733 , p. 21.

8. Burch, G. E., C. T. Ray, and J. A. Cronvich. Certain 
mechanical peculiarities of the human cardiac pump in normal and diseased states. Circulation 1952, 5, 504.

9. Burton, A. C. The importance of the shape and size of the heart. Amer. Heart J. 1957, 54, 801.

10. Elliott, S. E., J. I. E. Hoffman, and A. Guz. An electromagnetic flowmeter for simultaneous measurements of pulmonary arterial and aortic blood flows in the conscious animal. Medical Electronics and biological Engineering 1963, 1, 323.

11. Chapman, C. B., O. Baker, and J. H. Mitchell. Left ventricular function at rest and during exercise. J. clin. Invest. 1959, 38, 1202.

12. Holt, J. P. Estimation of the residual volume of the ventricle of the dog's heart by two indicator dilution technics. Circulat. Res. 1956, 4, 187.

13. Swan, H. J. C., and W. Beck. Ventricular nonmixing as a source of error in the estimation of ventricular volume by the indicator-dilution technic. Circulat. Res. 1960, 8, 989.

14. Rapaport, E., B. D. Wiegand, and J. D. Bristow. Estimation of left ventricular residual volume in the dog by a thermo-dilution method. Circulat. Res. 1962, 11, 803.

15. Wilcken, D. E. L. The measurement of the enddiastolic and end-systolic, or residual, volumes of the left ventricle in man, using a dye-dilution method. Clin. Sci. 1965, 28, 131.

16. Brockenbrough, E. C., and E. Braunwald. A new technic for left ventricular angiocardiography and transseptal left heart catheterization. Amer. J. Cardiol. 1960, 6, 1062.

17. Gorlin, R., E. L. Rolett, P. M. Yurchak, W. C. Elliott, F. J. Lane, and R. H. Levy. Left ventricular volumes in man measured by thermodilution. J. clin. Invest. 1964, 43, 1203.

18. Folse, R., and E. Braunwald. Determination of fraction of left ventricular volume ejected per beat and of ventricular end-diastolic and residual volumes. Experimental and clinical observations with a precordial dilution technic. Circulation 1962, 25, 674.

19. Bristow, J. D., R. L. Crislip, C. Farrehi, W. E. Harris, R. P. Lewis, D. W. Sutherland, and H. E. Griswold. Left ventricular volume measurements in man by thermodilution. J. clin. Invest. 1964, 43, 1015.

20. Chapman, C. B., O. Baker, J. Reynolds, and F. J. Bonte. Use of biplane cinefluorography for measurement of ventricular volume. Circulation 1958, 18, 1105.

21. Bruce, T. A., and C. B. Chapman. Studies on left ventricular volume (abstract). Clin. Res. 1960, 8, 178.

22. Sandler, H., H. T. Dodge, R. E. Hay, and C. E. Rackley. Quantitation of valvular insufficiency in man by angiocardiography. Amer. Heart J. 1963, 65, 501.

23. Dodge, H. T., H. Sandler, D. W. Ballew, and J. D. Lord, Jr. The use of biplane angiocardiography for the measurement of left ventricular volume in man. Amer. Heart J. 1960, 60, 762.
24. Rushmer, R. F., and N. Thal. The mechanics of ventricular contraction. A cinefluorographic study. Circulation 1951, 4, 219.

25. Hawthorne, E. W. Instantaneous dimensional changes of the left ventricle in dogs. Circulat. Res. 1961, 9, 110.

26. Charlier, A. A., D. E. L. Wilcken, A. Guz, and P. Sleight. Relation between stroke volume, flow patterns and diastolic filling time in conscious dogs. Fed. Proc. 1962, 21, 103.

27. Barnett, G. O., J. C. Greenfield, Jr., and S. M. Fox III. The technique of estimating the instantaneous aortic blood velocity in man from the pressure gradient. Amer. Heart J. 1961, 62, 359.

28. Porjé, I. G., and B. Rudewald. Hemodynamic studies with differential pressure technique. Acta physiol. scand. 1961, 51, 116.

29. Rudewald, B. Hemodynamics of the human ascending aorta as studied by means of a differential pressure technique. Acta physiol. scand. 1962, 54, suppl. 187.

30. Hefner, L. L., L. T. Sheffield, G. C. Cobbs, and W. Klip. Relation between mural force and pressure in the left ventricle of the dog. Circulat. Res. 1962, 11, 654.

31. Levine, H. J., and N. A. Britman. Force-velocity relations in the intact dog heart. J. clin. Invest. 1964, 43, 1383.

32. Rushmer, R. F., D. L. Franklin, and R. M. Ellis. Left ventricular dimensions recorded by sonocardiometry. Circulat. Res. 1956, 4, 684.

33. Wilson, M. F. Left ventricular diameter, posture, and exercise. Circulat. Res. 1962, 11, 90.

34. Hill, A. V. The absolute mechanical efficiency of the contraction of an isolated muscle. J. Physiol. (Lond.) 1913, 46, 435.

35. Hartree, W., and A. V. Hill. The factors determining the maximum work and mechanical efficiency of muscle. Proc. roy. Soc. B 1928, 103, 234.

36. Britman, N. A., and H. J. Levine. Contractile element work. A major determinant of myocardial oxygen consumption. J. clin. Invest. 1964, 43, 1397.

37. Braunwald, E., and M. M. Aygen. Idiopathic myocardial hypertrophy without congestive heart failure or obstruction to blood flow. Clinical, hemodynamic and angiocardiographic studies in fourteen patients. Amer. J. Med. 1963, 35, 7.

38. Bing, R. J., A. Siegel, A. Vitale, F. Balboni, E. Sparks, M. Taeschler, M. Klapper, and S. Edwards. Metabolic studies in the human heart in vivo. 1. Studies on carbohydrate metabolism of the human heart. Amer. J. Med. 1953, 15, 284.

39. Blain, J. M., H. Schafer, A. L. Siegel, and R. J. Bing. Studies on myocardial metabolism. VI. Myocardial metabolism in congestive failure. Amer. J. Med. 1956, 20, 820.

40. Linzbach, A. J. Heart failure from the point of view of quantitative anatomy. Amer. J. Cardiol. 1960, 5, 370. 